\title{
Atores não-estatais e meio ambiente nas relações internacionais: Greenpeace e a Antártica
}

\section{Actors who not pertain to the state, and dealing with environmental issues in international relations: Greenpeace and the Antarctic}

\author{
Rafael A. Duarte VILLA*
}

\begin{abstract}
RESUMO
O artigo analisa a crescente importância que vem tomando nas relações internacionais os atores nãoestatais transnacionais. Especificamente, o autor explora o caso dos atores ecológicos através de um estudo de caso: a ação do grupo Greenpeace na Antártica na década de 80. A hipótese central da pesquisa é que os atores não-estatais transnacionais, a exemplo dos grupos ecológicos, revisam a noção do enfoque realista da política internacional segundo a qual o monopólio das relações internacionais pertence ao Estado nacional. Congruente com tal hipótese, a emergência do ator não-estatal ecológico vai no sentido de questionar essa noção e abrir espaço para o surgimento de um sistema internacional plural quanto a seus atores e sua agenda de questões. A conclusão aponta para um envolvimento cada vez mais crescente, no nível internacional e nacional, desse tipo de ator não-estatal em arenas diferenciadas da dimensão estratégico-militar. Este estudo foi feito com base na interação desse grupo ecológico com o sistema de estados reunidos em torno do Tratado Antártico.
\end{abstract}

Palavras-chaves: Estados, atores não-estatais, Antártica, Greenpeace, Tratado Antártico

\begin{abstract}
This article analyses the growing importance transnational, non-statal actors has taken in international relationships. Specifically, the author explores the case of environmental actors discussing a case study: Greenpeace's action in Antarctic, during the 1980's. The main hypothesis states that transnational, non-statal actors, just like environmental groups, forces a reviewing of the realistic approach to the
\end{abstract}

* O autor é professor adjunto da Universidade Federal do Paraná-Brasil. 
VILLA, R. A. D. Atores não-estatais e meio ambiente nas relações internacionais...

theory of international relationships, according to whom the monopoly of those international relationships belongs to the national State. According to that hypothesis, the emergence of transnational, non-statal actors defies the realistic notion, and opens space for an international system that is plural for its actors and agenda. The conclusion sets for a growing commitment, at national and international levels, for that kind of non-statal actor, in an arena different from the stractegic-military one. So, this study has been made considering the interaction of Greenpeace and the State system organized to the Antarctic Treaty.

Key-words: State, non-statal actors, Antarctic, Greenpeace, Antarctic Treaty

No pensamento realista, as relações internacionais são definidas como "relações interestatais", o que indica que, nessa concepção, o ator fundamental no plano internacional é o Estado-nação, e os atores não-estatais são relegados à condição de "ambiente" da política interestatal. Na base dessa última assumpção está a idéia de que, no confronto dos atores transnacionais não-estatais com o Estado-nação, as razões deste último tendem a prevalecer. Essa hipótese não é errada. Os Estados, em confronto com outros atores do sistema internacional, prevalecem em função do maior poder relativo de que dispõem e também da maior legitimidade face às sociedades que representam. No entanto, os meios pelos quais o Estado nacional prevalece, o da coação e da legitimidade, nem sempre são eficientes, dado que os custos gerados pelo prevalecimento do seu caráter soberano podem ultrapassar os ganhos. Neste século, por exemplo, países do Terceiro Mundo (como o México de Cárdenas, em 1940; o Irã de Mossadegh, em 1951; e a Venezuela do primeiro governo de Carlos Andrés Pérez, em 1976) puderam nacionalizar as suas indústrias petrolíferas e até expulsar as multinacionais do ramo, mas os custos posteriores em investimento de capital, contratos de serviços e pacotes tecnológicos trouxeram-lhes onerosos débitos. Esses efeitos perversos abrem assim mais espaço para a barganha entre o ator estatal e o transnacional.

Como constata Gilpin ${ }^{1}$ novos tipos de atores transnacionais, mais sensíveis à moderna ciência, à tecnologia e às mudanças econômicas e ecológicas, têm quebrado o monopólio do Estado na administração e governo do sistema internacional, respondendo às profundas mudanças nos padrões da tecnologia - sobretudo nas comunicações e no transporte - que fizeram com que as socie- dades nacionais se voltassem para a problemática contida nos temas que afetam o bem-estar econômico, a saúde física e psíquica dos indivíduos de outras sociedades além das fronteiras. A revolução nas telecomunicações (TV, satélites, microinformática), bem como a acelerada modernização dos transportes (aviões, navios e automotores), tornaram possível que cidadãos e políticos "vissem" a agregação de microações em macrorresultados. As sociedades passaram a poder observar, ao vivo, pronunciamentos oficiais, a resposta dos adversários, os comentários dos manifestantes, a fuga dos refugiados e outras variedades de acontecimentos que conduzem a consenso, apoio ou rejeição das posturas abordadas. ${ }^{2}$ Enfim, a celeridade das mudanças nas comunicações e nos transportes tende a se acentuar, trazendo a idéia da "aldeia global" para um nível mais concreto. Pense-se na revolução que as chamadas "auto-estradas eletrônicas" ou redes internet estão suscitando na década de 90.

Tomassini ${ }^{3}$ elenca um conjunto de características que renovam e redefinem o papel dos atores não-estatais nas relações internacionais contemporâneas. De acordo com esse autor, as relações internacionais contemporâneas apresentam, em primeiro lugar, grande diversificação de centros de poder, cuja atuação deixa de ser pensada em função do Estado para incorporar a sociedade civil organizada. Em segundo, surge uma agenda de discussões internacionais ampliada e menos hierarquizada, isto é, a sua definição é menos centralizada. Finalmente, as novas problemáticas são geridas por múltiplos agentes distintos do Estado. Em decorrência disso, colocam-se em cena formas de poder nãotradicionais, em uma arena mais abrangente e diferenciada. Em outras palavras, parecem consolidar-se os cruza-

1 GILPIN, R. War and change in world politics. Cambridge: Cambridge University Press, 1989.

2 ROSENAU, J. N. Citizens in a changing global order. In: ROSENAU, J. N.; OTTO CZEMPIEL, E. (Eds.). Governance without government: order and change in world politics. Cambridge: Cambridge University Press, 1992.

3 TOMASSINI, L. El proceso de trasnacionalización y las relaciones externas de América Latina. In: TOMASSINI, L. (Comp.). Trasnacionalización y desarrollo nacional en América Latina. Buenos Aires: Grupo Editor Latinoamericano, 1984.

4 ARON, R. Os últimos anos do século XX. p. 27. 
mentos de processos interestatais, transnacionais e supranacionais, já descritos no conceito de "sociedade internacional ou mundial". Aron, em Os últimos anos do século, descreve o conceito de "sociedade internacional ou mundial", como "uma totalidade que incluiria ao mesmo tempo o sistema interestatal, o sistema econômico e os movimentos transnacionais, as sociedades e as instituições supranacionais". ${ }^{4}$

Neste ponto, interessa descrever o tipo de ator transnacional que se articula nos processos sociais globais e que interage com os outros planos da "sociedade mundial". De acordo com diferentes autores, o agente transnacional tem sido definido como "forças", 5 "unidades sociais", 6 "atores sociais" ou "microator". ${ }^{8}$ Uma definição abrangente de ator transnacional poderia ser como segue: "agente societal que estabelece um tipo inovador de vinculações extra-estatais, baseando-se em contatos, coligações e interações através das fronteiras nacionais ante os quais os órgãos centrais da política externa estatal ou supranacional têm relativa, ou nenhuma, capacidade regulatória”. Com relação aos tipos concretos de atores, parece existir, contemporaneamente, um consenso de que os dois tipos principais são as empresas multinacionais (EMNs) e as organizações não-governamentais (ONGs). Por razões de espaço, neste artigo, a análise se dirige às segundas. Especificamente, trata-se de explicitar um estudo de caso que tem como contexto empírico a discussão sobre as possibilidades de mineração na Antártica. Este exemplo mostra bem uma tendência que começa a tomar conta da agenda internacional: a interação crescente entre atores estatais e transnacionais (no caso atores ambientalistas) quando o tema em discussão cai fora do âmbito estratégico-militar, arena esta que segue reservada ao âmbito estatal.

\section{Mineração e internacionalização da Antártica}

A Antártica, com 14 milhões de quilômetros quadrados e $70 \%$ das reservas mundiais de água foi considera- da, por muito tempo, como um espaço de influência marginal em relação à interação global de elementos políticos, econômicos e estratégicos do sistema internacional. Esta percepção marginal, porém, começaria a mudar no final dos anos 50 de uma forma até certo ponto sui generis: no contexto internacional da Guerra Fria, a Antártica foi, possivelmente, o único território, incluindo continentais e peninsulares, onde os superpoderes chegaram a um consenso mínimo para poupá-la dos efeitos daquela. Neste sentido, sob a iniciativa norte-americana, assina-se, em 1959, o Tratado Antártico ${ }^{9}$ por motivo do Ano Geofísico Internacional. Sua disposição mais importante refere-se ao "congelamento" das reivindicações de soberania sobre o continente antártico, o que foi muito importante, levando em conta ser a Antártica a única porção geográfica do planeta onde ainda é possível qualquer Estado fazer reivindicações territoriais. Existem duas posições básicas em torno deste problema: 1) a dos países membros do sistema antártico com pretensões de soberania (Argentina, Chile, Inglaterra, Nova Zelânda, França, Noruega e Austrália); 2) a dos países liderados por Malásia, que propiciam uma internacionalização da Antártica sob a figura de patrimônio comum da humanidade.

Nas duas últimas décadas, o sistema internacional, limitado ao tradicional objeto das relações de poder entre Estados-nações, começou a ampliar sua agenda com o surgimento de novos temas como o caso do ecologismo. Como resultado, começaram a surgir e consolidar-se atores não-estatais que não só se preocuparam em representar seus interesses no interior do sistema político nacional, mas também mostraram preocupação crescente em influenciar os processos de tomadas de decisão internacional nos assuntos de sua competência. Neste novo quadro internacional está inserido a Antártica. A ampliação da agenda das relações internacionais mostra que a questão antártica não pode ser limitada, a priori, a seus aspetos de soberania ou internacionalização. A problemática da Antártica articulase, hoje, na perspectiva do crescente interesse que vem despertando a questão ecológica. A Antártica, neste marco, passou a ser um teatro onde se desenvolve uma ampla ati-

5 Cf. HOFFMAN, S. International organizations and the international system. International Organization, v. 24, n. $2,1969$.

6 Cf. MENDERSHAUSEN, H. Transnational society vs. state sovereignity. Kiklos, v. 21, n. 2, 1969.

7 Cf. KAISER, K. Transnational politics: toward a theory of multionational politics. International Organization, v. 25 , n. 3, Autumn 1971.

8 Cf. ROSENAU, op. cit.

9 Os países pertencentes ao tratado são dividos em consultivos (com direito a voze voto) e não-consultivos (só com direito a voz). Para adquirir o status de consultivo é necessário que um país instale uma base científica e faça pesquisa relevante. Até início desta década, eram consultivos: Argentina, Inglaterra, Brasil, França, Chile, Bélgica, Japão, China, Sul-África, USA, Rússia, Austrália, Polônia, Uruguai, Coréia do Sul, Suécia, Finlândia, China, India, Itália, Peru, Espanha, Alemanha e Noruega. 
VILLA, R. A. D. Atores não-estatais e meio ambiente nas relações internacionais...

vidade de atores não-estatais preocupados com os desequilíbrios ecológicos que uma eventual exploração de seus recursos minerais poderia gerar no âmbito mundial.

De todas as atividades passíveis no Sistema do Tratado Antártico, a de maior conotação política, portanto a mais polêmica, refere-se às projeções de uma futura exploração de recursos minerais na Antártica. Strictu sensu, foi essa problemática que fez a sociedade internacional tomar um grande interesse pelos assuntos antárticos a partir da década passada.

A polêmica tem seu ponto de partida nas especulações sobre o potencial quantitativo dos recursos minerais presentes no continente antártico. Sabe-se hoje da existência, no subsolo antártico, de importantes depósitos de minerais duros como ferro e aço, entre outros, e, em menor quantidade, ouro, cobre, níquel, titânio e urânio. No presente, parece não existir viabilidade, em preços correntes e tecnologia, para a exploração comercial desses minerais:

En 1978 llegamos a la conclusión de que las perspectivas para la explotación de minerales duros en tierra, en el futuro previsible, eran mínimas y essa conclusión todavia tiene vigencia, de acuerdo con informe reciente realizado pelo US Geological Survey (USGS), que encuentra un futuro poco promisorio para tales minerales. ${ }^{10}$

Se isso é certo para o caso dos minerais duros, a mesma conclusão não é válida para o caso dos hidrocarbonetos:

El término recursos minerales es amplio. Sabemos mucho más sobre minerales duros del continente antártico que sobre hidrocarburos. Sin embargo, el foco deveria estar en el petróleo y el gas, posto que existe un acuerdo casi universal sobre que existen pocas perspectivas de recuperación económica de minerales. ${ }^{11}$

Embora não exista consenso nas pesquisas geológicas sobre a existência atual de hidrocarbonetos na Antártica, não parecem existir dúvidas de que, caso existam os depósitos, apresentariam condições viáveis para sua exploração a médio prazo. Drugger, comentando pesquisas do US Geological Survey aponta:

El interés sigue enfocado en el petróleo y el gas de las plataformas continentales: investigaciones continuas poco han hecho por afinar las estimaciones del potencial de hidrocarburos. La circular, de 1983, del US Geological Survey concluye que no existen recursos petrolíferos en la Antártica en el presente, y la industria del petróleo no está particularmente interesada. No obstante, continua la circular, consideraciones económicas y políticas pueden mudar los intereses de la industria. La exploración sería posible dentro de una o dos décadas. ${ }^{12}$

Em época mais recente, 1987, Geotrie Larminie diretor do British Geological, concluía que as perspectivas de aproveitamento comercial de hidrocarbonetos na Antártica eram bem remotas; igual opinião era sustentada por Lord Shackleton, um dos mais conotados estudiosos dos recursos do oceano Austral, que desaconselhava qualquer interesse comercial na região.

Ora, independente das certezas e incertezas da extensão do potencial ou dos obstáculos climáticos, comerciais e tecnológicos para sua exploração, o tema dos minerais antárticos é altamente sensível a diversos atores internacionais. $\mathrm{O}$ fato de o Tratado Antártico não incluir sua discussão refletia quanto o tema era delicado. Falar em exploração de minerais, num momento em que o Tratado era interpretado como um passo para a internacionalização, teria sido um erro diplomático de alto custo da parte dos promotores do Tratado perante os Estados reivindicantes de soberania.

Este cuidado extremo com o assunto dos recursos minerais refletia, por outra parte, quanto os aspectos econômicos, sobretudo no que diz respeito à exploração de petróleo, era o assunto mais relevante a ser considerado, pelo menos até princípios da década de 80 . Pensava-se então que as respostas às perguntas de quando e como o petróleo e o gás da Antártica seriam, fatalmente, explo-

10 DUGGER, J. A. Una mirada hacia las perspectivas del petróleo y el gas en la Antártida. In: MONETA, C. (Ed.). La Antártida en el sistema internacional del futuro. Buenos Aires: Grupo Editor Latinoamericano, 1988. p. 214.

11 Ibid., p. 211.

12 Ibid., p. 213.

13 Ibid., p. 213-214. 
rados decorreria das necessidades da economia. O descobrimento de significativos recursos de hidrocarbonetos em outras áreas do mundo, a estabilização dos preços mundiais do petróleo, os prognósticos de demanda menor e o desenvolvimento de fontes generalizadas de energia seriam fatores que estariam contribuindo para adiar o momento no qual precisar-se-ia do petróleo da Antártica. $^{13}$

Apesar de todas estas ponderações, o sistema do Tratado Antártico avançou na direção de elaborar e aprovar um regime que regulasse a exploração de minerais antárticos. As negociações para o estabelecimento desse regime começaram em 1970 (na reunião Consultiva de Tóquio); embora o desmentido das Partes Consultivas e o hermetismo com que guardam suas decisões, no presente conhece-se bem que durante toda a década do 70 estabeleceram-se algumas linhas gerais do futuro regime de minerais. Esta iniciativa das Partes Consultivas refletia a preocupação com a crise petrolífera da época:

Antes del embargo árabe de 1973, havia un leve tufo a petróleo en el Sistema del Tratado Antártico, cuando la Septima Reunión Consultiva de 1972 recomendó que los recursos antárticos y los efectos de la exploración mineral fueran estudiados y puestos en la agenda de la siguiente Reunión Consultiva. En el momento de la Octava Reunión Consultiva, en 1975, todo el mundo estaba preocupado con la energia, en particular el petróleo, y havia verdadera preocupación de que el Sistema del Tratado pudiese desmembrarse devido al descubrimiento de hidrocarburos en la Antártica. ${ }^{14}$

Tendo em vista esta preocupação, na IX Consultiva de Londres (1977), aprovou-se o princípio de “abstenção voluntária” (Recomendação IX-1), pelo qual as Partes Consultivas comprometiam-se a não efetivar e a controlar as atividades vinculadas com o reconhecimento e exploração dos recursos mineiros. Com esta decisão procurava-se conter uma precipitada corrida, influenciada pela crise energética de 70, para a exploração petrolífera antártica. Ora, o termo "restrição voluntária" deve-se mais a uma interpretação do texto, posto não ser usado formalmente na Recomenda- ção. Aliás, o termo, acredita Auburn, disfarça uma moratória sobre os minerais antárticos:

Puede sugerirse que la frase se originó en el Departamento de Estado, que se oponía a una moratória formal. Puede sugerirse que un factor de mayor peso, en la interpretación oficial de los Estados Unidos de la Recomendación IX-1 poderia haver sido que, admitir que el Departamento de Estado votó en favor de una moratória sobre exploración de petróleo, en cualquier territorio con respecto al cual los Estados Unidos tuviesen alguna forma de pretensión, huviese tenido serias repercusiones políticas en un momento que la Organización de Países Exportadores de Petróleo (OPEP) tenía el control total del precio del petróleo. ${ }^{15}$

Mas mesmo que a recomendação IX-1 fosse obrigatória, algumas partes tem feito o que se chama de exploração comercial básica. Em 1977, O relatório técnico da IX Consultiva concluía não haver nada que evitasse a exploração básica de recursos de gás e petróleo, já que a exploração básica implica muitas atividades inseparáveis da pesquisa científica-geológica e geofísica. Com este argumento em mente foi enfocada a expedição Ahakurei Maru da Japanese Oil Company. Outras nações também não fizeram segredo de seu interesse nos potenciais recursos minerais da Antártica. Exemplo disso, que a então União Soviética estabeleceu no Mar de Wedell, em 1975, a primeira estação, "a Druzhnaya", dedicada à prospeção de minerais. Em princípios de 80, a então Alemanha Oriental, os Estados Unidos e Noruega realizaram surveys sísmicos na área dos mares de Ross e Wedell.

A questão da discussão sobre a "abstenção voluntária" foi seguida pela definição de algumas normas para o futuro regime de minerais. A Recomendação XI-1, de Buenos Aires, as enumera da seguinte forma:

- Manutenção do Tratado Antártico;

- Papel ativo e responsável das Partes Consultivas;

- Proteção do ambiente antártico e de seus ecossistemas;

Este crescente interesse das Partes Consultivas pelos minerais antárticos não passou despercebido para a socie-

14 DUGGER, op. cit., p. 211

15 AUBURN, F. M. Los recursos de los océanos australes y los Estados Unidos. In: MONETA, C. (Ed.). La Antártida en el sistema internacional del futuro. Buenos Aires: Grupo Editor Latinoamericano, 1988. p. 103. 
VILLA, R. A. D. Atores não-estatais e meio ambiente nas relações internacionais...

dade internacional. A tese da internacionalização da Antártica, levantada com tanto vigor pela Malásia, Antiga e Barbuda, no seio da Assembléia Geral da ONU, deve ser interpretada como uma reação de um setor do Terceiro Mundo (de escassos recursos científicos, tecnológicos, econômicos e com pouca força política no balanço internacional) frente ao interesse que os assuntos da mineração estavam despertando nas Partes Consultivas. O raciocínio indicava-lhes que se fosse iniciada uma corrida pelos recursos minerais da Antártica o mais provável é que ficassem de fora na partilha do produto da exploração. Neste sentido, o conceito de "patrimônio comum da humanidade", sob o qual impulsionavam a internacionalização da Antártica não deixava de ser, portanto, discursivo, ocultando os verdadeiros propósitos da proposta.

Mesmo assim, fora da conotação semântica e sim política, que é o que aqui interessa, o conceito de internacionalização só tem possibilidade de articular-se com sucesso em foros diplomáticos amplos. Sendo assim, a pressão diplomática daqueles países terceiro-mundistas dirigiu-se à Assembléia Geral da ONU, baseados na convicção de que a internacionalização sob o princípio de "patrimônio comum da humanidade" encontraria uma melhor recepção no seio deste organismo. Como expressa, com todo realismo, um pesquisador da Malásia:

Dado que el desarrollo de los recursos está fuera de la jurisdicción del Tratado, sus miembros no tienen ninguna razón válida para protestar si las Naciones Unidas declaran que estos recursos son herencia comúm de la humanidad. Ciertamente, estos recursos no están sujetos a la apropiación nacional. ${ }^{16}$

A pressão daquele pequeno grupo de países do Terceiro Mundo viu-se recompensada por uma resolução aprovada pela ONU, na qual lê-se que, toda exploração dos recursos da Antártica devem garantir a manuntenção da paz e da segurança da Antártica, a proteção de seu meio ambiente, a não-apropiação e a conservação de seus recursos e a administração internacional e o reparto eqüitativo dos benefícios da exploração (sublinhado meu).

O importante desta resolução, não só permite a institucionalização da reivindicação da internacionalização, senão que permite estabelecer os princípios que deveriam presidir a prospecção e exploração dos recursos minerais antárticos: a não-apropriação e sim a conservação, a administração internacional e o reparto eqüitativo dos benefícios da exploração.

\section{Antártica e ecologia: a perspectiva dos atores es- tatais e não-estatais}

As discussões sobre o regime de minerais e a tese da internacionalização, até aqui, indicavam que o futuro da Antártica estaria dominado por um raciocínio estritamente econômico. No entanto, paralelamente, desenvolvia-se um debate sobre os efeitos de uma possível exploração mineral na sua biosfera. Este debate era promovido por entidades não-governamentais como a Fundação Fridtjof Nansen, que, já em 1973 - talvez como reflexo da Conferência da ONU sobre Meio Ambiente Humano, de 1972 -, se adiantou nos estudos de impacto ambiental na Antártica através de um simpósio realizado na Noruega. Também em 1973, a Fundação Rockefeller, na Itália, promoveu uma reunião de especialistas em recursos minerais antárticos. Estas iniciativas fizeram com que as Partes consultivas, pela Recomendação VIII-14 de Paris (1976) organizassem dentro do SCAR (Comitê Científico para o Estudo dos Recursos Antárticos) o grupo denominado E.A.M.R.E.A (Grupo de Especialistas para a Avaliação do Impacto Ambiental da Exploração dos Recursos Minerais Antárticos).

Face a uma futura exploração de minerais na Antártica, é bem provável que a questão do impacto ambiental não fosse ignorada por nenhuma das partes (leia-se Estados) interessadas economicamente. É possível sugerir duas repostas que explicam este lapsus durante um certo tempo: primeiro, existia a convicção de que as considerações econômicas acabariam prevalecendo sobre as questões ambientais. Esta era uma opinião quase generalizada até meados da década passada. Uma segunda consideração era a de que os elementos geradores de algum impacto ambiental - presença humana e turismo - seriam minimizados. $\mathrm{O}$ ecossistema do continente antártico tem sido atingido, sem dúvida, em muito menor grau, pelas atividades humanas que em outros continentes. Acontece, porém, que a cada ano são levadas à Antártica toneladas 
VILLA, R. A. D. Atores não-estatais e meio ambiente nas relações internacionais...

de carregamento de material e produtos diversos assim como milhões de galeões de combustível, sendo que depois uma parte desta matéria removida permanece à exposição ambiental, sob a forma de construções abandonadas, chacina e resíduos sólidos. Por outra parte, a combustão de milhões de litros de petróleo e gasolina, a cada ano, libera para o ar alguns gases como bióxido de carbono, óxido nitroso, óxidos sulforosos, hidrocarbonetos e partículas. Alguns desses gases são incorporados nos mares, gelo, neve e solo antártico.

Porém, seria o grupo Ecológico Greenpeace ${ }^{17}$ que se encarregaria de fornecer as provas sobre as práticas pouco conservacionistas desenvolvidas pela maior parte dos países com bases instaladas na Antártica. Em 1988, o Greenpeace produziu um substantivo relatório, produto de sua expedição antártica $1987-1988,{ }^{18}$ demonstrando que a quase totalidade das bases presentes na Antártica não só não cumpriam o Código de Conduta para Bases e Expedições senão que, além disso, inauguraram práticas como a queima de lixo a céu aberto, inclusive de plásticos, o despejo de esgoto, sem prévio tratamento das bacias circundantes, e a disposição de resíduos no gelo na espera do derretimento na primavera. A minuciosa inspeção do Greenpeace constatou, como já o tinha feito a Science National Foundation dos Estados Unidos (NSF), que as bases Palmer e McMurdo destes países não cumpriam o Código de Conduta no que diz respeito à disposição de resíduos. Neste sentido, o Greenpeace recomendava que "la NSF deveria preparar y hacer público un plano integral de limpieza para todas las estaciones de los Estados Unidos". ${ }^{19}$ Mas as bases norte-americanas não são a exceção. Das 28 bases visitadas por Greenpeace só três - Brasil, Itália e Polônia - receberam comentários satisfatórios. ${ }^{20} \mathrm{Re}$ servou-se ao resto, em maior ou menor medida, um diagnóstico parecido àquele das norte-americanas:

Las condiciones en que se encontraron las bases variaron de forma significativa. En la mayoría de ellas, por lo menos en un aspecto, para la disposición de resíduos, no cumplen el Código de Conducta. En general, las bases de los países con mayor permanencia en la Antártica son las que presentan más problemas con relación a este tema. ${ }^{21}$

O relatório do Greenpeace também ajuda a desvendar outros mitos sobre a atitude conservacionista das Partes Consultivas. Por exemplo, o pessoal de algumas bases desconhece, ou tem conhecimento vago, das Recomendações práticas contidas no Sistema do Tratado Antártico. Isto foi evidente no caso da base chinesa "Grande Muralha":

Cuando Greenpeace especificó que los plásticos deben ser removidos de la Antártica, el personal de la base se mostró algo confuso. Eso tal vez implique que no tenían conocimiento de la existencia del Código de Conducta o que si lo conocían no eran conscientes de su importancia (...) A pesar del personal de la base, al que se le preguntó por los SEIC (Sitios de Especial Interés Científico), no comprender de que se tratava, hablaron de la existencia de una área a la que no se podía ingresar. Cerca de la base había un letrero indicando la prohibición de ingresar en esa área, pero en el resto del perímetro la Zona Especialmente Protegida no estaba demarcada. ${ }^{22}$

Outra questão importante - ou omissão - destacada pelo relatório era a pouca relevância dada aos Estudos de Impacto Ambiental (EIA) quando se trata de instalar uma base, o que ficou evidente na inspeção feita a algumas bases de mais recente instalação, como as do Uruguai e Espanha, que, logicamente, careciam de um mínimo EIA.

Não menos preocupante era o fato de não se contar com esse tipo de estudos para o diagnóstico de impacto ambiental que os esgotos podem causar nas bacias antárticas. Citando o comandante americano (Lacount) da McMurdo, o relatório anota:

\footnotetext{
17 Greenpeace é a única organização não-governamental que conta com uma base na Antártica, a "World Park", estabelecida em 1987, mas as atividades do Greenpeace na Antártida iniciaram-se em 1982, propondo desde então transformar a Antártica num "parque mundial".

18 GREENPEACE. Informe de la Expedición Antárctica de Greenpeace. 1987/1988. Buenos Aires: Greenpeace Argentina, 1988.

19 Ibid., p. 64. Por outro lado, essa atitude negligente dos Estados Unidos não deixa de ser um paradoxo para um país que apresenta os Estudos de Impacto Ambiental (EIA) mais desenvolvidos do mundo.

20 Ibid., p. 18; 52; 56.

21 Ibid., p. 76.

22 Ibid., p. 28.
} 
VILLA, R. A. D. Atores não-estatais e meio ambiente nas relações internacionais...

Según las informaciones con que cuenta Greenpeace, los desechos cloacales y otros residuos son vertidos al mar sin previo tratamiento. Cuando se le preguntó a Lacount si el nuevo Informe sobre Impacto Ambiental incluiría una evaluación del impacto causado por los desechos cloacales vertidos en la Bahia de McMurdo, la respuesta fue "provavelmente no". Cuando se le preguntó acerca de la influencia que tendrían estos residuos en la biologia de las aguas circundantes, Lacount respondió que, según su entender estos residuos no acarreaban ningún impacto, lo que se contradice con el documento de impacto escrito por Dayton e Robbilliard (Antarctic Journal, mayo/jun. 1971) en el que los autores expresaban que la contaminación orgánica que resulta de los residuos de alimentos y desechos cloacales acumulados en el medio marino son en potencia extremamente nocivos para las comunidades antárticas. ${ }^{23}$

Todas essas evidências começaram a gerar muita desconfiança nos setores ambientalistas. Se as atividades científicas, raciocinava-se, são capazes de gerar poluição tóxica (a partir de resíduos humanos e não-humanos), os estragos de uma futura exploração comercial mineral poderiam ser muito piores. ${ }^{24}$ Esta mesma conclusão foi recolhida no relatório do Greenpeace:

El impacto que ocasionan las bases - inclusive las científicas - reafirma la creencia de que si se exploran minerales en este continente virgen, la vida silvestre y el ambiente antártico se verían seriamente afectados. Vale la pena tomar en cuenta que no será más posible ejercer mayor control sobre las actividades minerales que aquel que se ejerce sobre las actividades científicas. Si en las condiciones actuales no es posible para todas las partes cumplir con las reglas establecidas para el comportamiento del hombre en la Antártica, las perspectivas para el futuro no son muy estimulantes. ${ }^{25}$
Entre 1982 e 1988, as Partes Consultivas discutiram a aprovação de uma convenção que regulasse a futura exploração e comercialização de minerais na Antártica. Na XIV Consultiva de Wellington, de julho de 1988, redigiuse um rascunho de acordo chamado de "Convenção para a Regulamentação das Atividades sobre os Recursos Minerais Antárticos". A Convenção esquematizava os seguintes princípios a serem seguidos com relação às atividades sobre recursos minerais antárticos: $:^{26}$

- a proteção do meio ambiente antártico e o ecossistema dependente;

- respeitar a importância e a influência da Antártica para o meio ambiente global;

- respeitar outros usos legítimos da Antártica.

Apesar destes princípios, a Convenção de Wellington, como era previsível, gerou uma ampla polêmica que envolveu tantos atores estatais como transnacionais e intergovernamentais:

O debate da questão ambiental aberto em torno da Convenção de Wellington ajudou a situar o eixo do verdadeiro problema. O dilema da questão antártica não passa hoje pela antinomia de uma internacionalização total do continente ou a divisão do continente em territórios soberanos, mas pelo conflito entre ecologia e soberania. Conflito complexo que até muito recentemente nenhum ator estatal, a favor ou contra o Tratado, intuía com a mesma lucidez com que nos anos 50 se percebeu a relação conflitiva entre paz e soberania. ${ }^{27}$

O real eixo da questão era bem mais amplo. Ele passava pelo debate mais extenso entre a antinomia soberania e ecologia. As negociações sobre a Convenção de Wellington revelam, na verdade, um dilema entre o incremento do interesse nacional dos países do Tratado Antártico e os interesses ecológicos. Isto é claro no caso de países como Estados Unidos, que no passado assumiu, no Siste-

\footnotetext{
23 GREENPEACE, op. cit., p. 13.

24 HEMMING, A. D. Antarctic the earths's fragile alarm bell. Our Planet, v. 2, n. 3, p. 6, 1990.

25 GREENPEACE, op. cit., p. 76.

26 Artigo 2 (3) do rascunho da Convenção de Wellington.

27 LEIS, H. Ecologia e soberania na Antártica. ENCONTRO DA ASSOCIAÇÃO NACIONAL DE PÓS-GRADUAÇÃO EM CIÊNCIAS SOCIAIS, 14., 1990, Caxambú. Anais... Caxambú: [s. n.], 1990.
} 
ma do Tratado Antártico, posições conservacionistas, mas que no presente encara-se com esse dilema:

El interés nacional de los Estados Unidos en el petróleo se distingue considerablemente de su interés en el krill. Sus objetivos requieren la seguridad de que tengan acceso no discriminatorio a los recursos minerales de la Antártica. A pesar del presente exceso de petróleo, no existen dudas de que el gobierno y la industria americana tienen interés serio y bien fundamentado por reservas de largo plazo y no sujetas a sanciones y otras medidas hostiles. ${ }^{28}$

Este dilema, entre interesse nacional e ecologia, segue existindo na medida que todas as partes estatais consultivas, não-consultivas e postulantes de internacionalização - pregam a preservação do meio ambiente antártico. Só que, enquanto uns tentam compatibilizar esta proteção com a defesa da mineração, outros tentam tornar compatíveis mineração, defesa do meio ambiente e interesses comuns da humanidade. Em outras palavras, tenta-se compatibilizar preservação ecológica com interesse nacional. Como preservação ecológica e interesse nacional são excludentes, no caso da Antártica, em algum momento da discussão da Convenção considerou-se que as Partes Consultivas resolveriam o dilema em favor do interesse nacional. Esta possibilidade decorria de um sólido argumento dos atores estatais do Sistema do Tratado Antártico: a inexistência da Convenção poderia gerar uma corrida descontrolada pela exploração mineral e uma conseqüente deterioração ambiental, pois considerava-se praticamente impossível renunciar à exploração econômica da Antártica. ${ }^{29}$

Os atores não-estatais que fazem pressão pela conservação e preservação do meio ambiente antártico, com a exceção compreensível das transnacionais da mineração, tinham também sólidos argumentos para contrapor aos ato- res estatais..$^{30}$ Para os ambientalistas, representados na Coalizão Antártica e no Oceano Ártico (ASOC), a corrida pela exploração mineral só seria possível se se garantissem os direitos de investimento e de propiedade. Como não existem esses direitos, argumentam, não se corre perigo de que a não existência da Convenção possa gerar tal corrida. A proposta concreta da ASOC passava então a estabelecer uma "Convenção para a Proteção Permanente do Ambiente Antártico", o que incluia transformar a Antártica num "parque mundial". ${ }^{31}$

Um Regime de Proteção Permanente é definido pelos ambientalistas como um "sistema administrativo internacional podendo ser aplicável desde a esfera legal para o manejo efetivo dos valores prístinos [sic] antárticos". ${ }^{32} \mathrm{Ba}-$ sear-se-ia este sistema nos seguintes princípios: proteção dos valores naturais; absoluta proteção de toda a vida silvestre e o ambiente; manutenção de uma zona de atividade científica, com especial ênfase na cooperação entre todos os cientistas das nações; manuntenção de uma zona de paz, livre de todo tipo de armas nucleares ou convencionais, e de todo tipo de atividade militar. A criação deste regime permanente prevê um monitoramento das seguintes atividades: desenvolvimento da pesquisa científica, turismo e exploração comercial de reservas de peixes e krill. De igual forma, o regime proibiria - além das atividades nucleares e militares - a exploração comercial dos recursos minerais, a disposição de resíduos tóxicos e nucleares e a morte de mamíferos marinhos e aves. ${ }^{33}$

Dois argumentos são apresentados para sustentar esta posição ambientalista: primeiro, a pesquisa científica para detectar mudanças globais na biosfera depende de uma Antártica intocada, uma vez que se ela sofresse alterações ambientais perderia a possibilidade de se utilizar como laboratório privilegiado de pesquisa. Segundo, além da poluição localizada e dos riscos para seus frágeis ecosistemas, conta também com o acréscimo da poluição global que se produziria pela exploração dos principais recursos do continente - petróleo, gás e carvão - no sistema produtivo

28 AUBURN, op. cit., p. 13.

29 LEIS, op. cit., p. 13

30 Observa-se uma gradual participação das empresas mineradoras e petrolíferas nas delegações dos Estados Unidos e Inglaterra nas reuniões das Partes Consultivas do Tratado Antártico. Para esta informação ver: MONETA, C. La Antártida y el Atlántico Sur en el sistema internacional. In: MONETA, op. cit., p. 14.

31 O ponto de vista da ASOC está contido nos seguintes documentos: ASOC. Protección permanente para a Antártida: se requiere com carácter urgente una convención para la reglamentación de las actividades minerales. Buenos Aires: Greenpeace, [19-]; ASOC. Análisis de la Convención para la Reglamentación de Actividades de Recursos Minerales Antárcticos. Buenos Aires: Greenpeace, 1988.

32 GREENPEACE. Declaração sobre a Antártica. Buenos Aires: Greenpeace, [19-]; GREENPEACE. Antártida en peligro: un problema que concierne al mundo; la opción de protección permanente para la Antártida. Buenos Aires: Greenpeace, [19-].

33 Ibid. 
VILLA, R. A. D. Atores não-estatais e meio ambiente nas relações internacionais...

internacional. São precisamente esses combustíveis fósseis os principais responsáveis pelo efeito estufa. ${ }^{34}$

Neste embate de posições, há dois fatos importantes: o já citado Relatório da Expedição Greenpeace 1987/1988 e o impacto que causou na opinião pública mundial o vazamento de petróleo de um petroleiro da Exxon Valdes em 1989, no Alaska, consolidando os argumentos dos ambientalistas. Esses dois fatos foram de importância fundamental. Tendo uma vinculação direta com as mudanças ambientais globais, ocasionaram uma alteração de posições no interior do Sistema do Tratado Antártico. Tal mudança veio se refletir diretamente no fortalecimento dos objetivos das ONGs ambientalistas:

Quando Greenpeace em 1982 se propôs a proteger a Antártica, através de um parque mundial, o "senso comum" (e a maioria dos internacionalistas) qualificava de utópico e politicamente impossível esse objetivo. No entanto, sete anos depois não foi o Greenpeace quem mudara senão importantes membros do Sistema do Tratado Antártico. ${ }^{35}$

Em 1989, dois países do Sistema do Tratado Antártico reivindicantes de soberania, França e Austrália, ${ }^{36}$ anunciaram que estavam abstendo-se de assinar a Convenção de Wellington. Em seu lugar, em declaração conjunta, passaram a propor a criação de uma "reserva internacional natural" - nature reserve, land of science - proposta semelhante à de um Regime Permanente de Proteção Ambiental ou parque mundial feita pelas ONGs ambientalistas. ${ }^{37}$

No caso da França, além das considerações sobre as mudanças ambientais globais, a sua mudança de posição foi influenciada pelo fortalecimento interno da green politics e por uma resolução do Parlamento Europeu, estimando que "convinha renunciar à exploração das riquezas minerais na Antártica". ${ }^{38}$

O caso da Austrália é também significativo, posto que, reivindicando $42 \%$ do território antártico, um dos prin- cípios básicos que orientava a sua política antártica era de que, apesar do reconhecimento das qualidades ambientais da região, a Austrália continuaria suas pesquisas sobre os recursos das regiões reivindicadas, enquanto mantinha a perspectiva da utilização desses recursos em data futura. ${ }^{39}$ Porém, a mudança de atitude australiana não surpreendeu e inclusive já era até prevista:

Hasta finales de la década de 1970, poca o ninguna oportunidad existió para la participación pública en la toma de decisiones sobre la Antártica. La realidad es que el pueblo australiano estaba más preocupado en el desarrollo de los recursos terrestres de su propia masa continental, al mismo tiempo que intentava resolver algunos problemas sociales recién descubiertos. Es sólo en tiempos más recientes que las divulgaciones de los medios masivos de comunicación han vertido luces sobre el futuro de la Antártica y las cuestiones asociadas a sus recursos marítimos. La creciente conciencia pública y el creciente activismo de los grupos ecológicos, sin dudas, llevaron a una reestructuración de los procesos de decisión: se aconsejaría a los políticos y a los burócratas, por igual, que reconozcan ese hecho. ${ }^{40}$

Sem chegar a uma posição ecocêntrica, a postura da França e Austrália deve ser interpretada como a renúncia a uma soberania real, dado que as reivindicações formais são garantidas pelo artigo 4 do Tratado Antártico. Deve-se lembrar que, segundo esse artigo, ato algum, de uma Parte Consultiva, implica em negação de reivindicações de soberania enquanto o Tratado vigorar. França e Austrália não deixam de ser coerentes com o Tratado, por suas posições conservacionistas, nem deixam nada ao acaso ou ao emocionalismo da "onda verde".

A posição dos dois países viu-se reforçada com a adesão de outras Partes Consultivas como a então União Soviética, Bélgica, Itália, Polônia, e Nova Zelânda. Esses países passaram, inclusive, a compartilhar da proposta do par-

\footnotetext{
34 LEIS, op. cit., p. 14.

35 Ibid., p. 15.

36 Juntos, esses dois países reivindicam quase o 45\% do território antártico, sendo que a Austrália reivindica $43 \%$.

37 Documento da declaração conjunta franco-australiana sobre a Antártida, Paris, 1989.

38 Parlamento Europeu. Doc. A2-57/87.

39 DAVIES, B. W. Austrália y Antártida: una relación que muda. In: MONETA, op. cit., p. 47.

40 Ibid., p. 52-53.
} 
VILLA, R. A. D. Atores não-estatais e meio ambiente nas relações internacionais...

que mundial. Nos casos da Bélgica, Itália, Polônia e Nova Zelânda, influíram nas suas decisões o impacto na opinião pública interna de fenômenos como o efeito estufa e a diminuição da camada de ozônio e, obviamente, o impacto da green politics. No caso da União Soviética, o interesse nacional não está orientado para a exploração de minerais - este país é um dos maiores produtores mundiais de petróleo -, mas para os recursos vivos antárticos e especialmente para o krill. Daí a posição deste bloco de países anexando posteriormente a Índia e a Espanha - ganhou força no mesmo ano de 1989, quando a questão antártica, considerada de novo pela Assembléia Geral da ONU, fez um chamado a todos os membros da comunidade internacional para "apoiar todos os esforços para banir a prospecção e mineração em torno da Antártica”, para assegurar que todas as atividades fossem exclusivamente usadas para o propósito da pesquisa científica, a manutenção da paz internacional, a segurança antártica e a proteção de seu ambiente. Na mesma data, o plenário da Assembléia Geral aprovou como Resolução, surpreendentemente, que a Antártica fosse transformada em uma reserva internacional. ${ }^{41}$

Esta Resolução, adotada pela Assembléia Geral da ONU, sem a presença das Partes Consultivas do Sistema do Tratado Antártico, é de uma singular importância. Desde 1983, quando a Assembléia Geral considerou pela primeira vez a questão antártica, o debate e suas resoluções haviam estado dominados pelas pressões dos países do Terceiro Mundo no sentido de internacionalizar a Antártica. Tal resolução nada diz em relação a esse ponto. Ao contrário, atenta para a transformação da Antártica numa "reserva internacional", proposição semelhante àquela das organizações não-governamentais ambientalistas, e a proposta do bloco das Partes Consultivas comandadas pela França e Austrália. A tese da internacionalização perdia, assim, força no seu principal foro, a Assembléia Geral da ONU. Essa virada para os aspetos conservacionistas na Antártica mostrava quanto o debate ecológico global, do qual a ONU, através do PNUMA (Programa Ambiental das Nações Unidas), tem sido um dos principais interlocutores, come- çava a ser levado a sério nas considerações interestatais.

Em outro bloco de Partes Consultivas, favoráveis à assinatura da Convenção de Wellington, alinhavam-se os Estados Unidos, Inglaterra, Argentina e Chile. No caso dos Estados Unidos, compreende-se o interesse nacional pelo petróleo, tal como já foi salientado. Mas no caso da Inglaterra - país produtor de petróleo - Argentina e Chile, além dos interesses geopolíticos que os anima, ${ }^{42}$ essa posição deve ser interpretada como uma forma de se opor ao surgimento de qualquer instância administrativa supranacional que diminua a força das já minguadas pretensões de soberania antártica. Também é certo que no caso da Inglaterra a sua posição guarda coerência com a tradição pós-Segunda Guerra Mundial de aliado quase incondicional dos Estados Unidos.

Levando em conta que no Sistema do Tratado Antártico todas as decisões devem ser tomadas por consenso, com a existência de posições contra a assinatura da Convenção de Wellington já para a XV Consultiva de Paris, 1989, tal convenção havia sido praticamente descartada. ${ }^{43}$ Com isso, a reunião das Partes Consultivas, de junho de 1991, quando o Tratado Antártico fez trinta anos e poderia ser emendado segundo seu artigo 12, gerou uma grande expectativa. Antes desse encontro, foi realizada, em abril de 1991, a Conferência Antártica de Madri, que confrontou a proposta franco-australiana - agora mais radicalizada, posto ter se acrescentado que a Convenção de Proteção Ambiental Permanente proibisse ad infinitum toda atividade de prospecção ou mineração - e a proposta norte-americana - apoiada pelo Japão, Alemanha e Inglaterra - de redigir um protocolo que deixasse aberta a possibilidade da mineração antártica no futuro próximo. As partes entraram desta forma num impasse devido à atitude intransigente de ambos lados. Mas as negociações levaram a uma proposta intermediária, que proibia por 50 anos qualquer atividade de prospecção ou exploração mineral na Antártica. Mesmo assim, a posição dos Estados Unidos seguiu irredutível. O impasse só se resolveu quando Japão e Alemanha - pressionados pela opinião pública interna - se

41 Citado por HEMMINING, op. cit., p. 6.

42 Deve-se considerar a superposição de reivindicações territoriais antárticas da Inglaterra, Argentina e Chile entre os meridianos 20 e 90 de longitude oeste e as projeções do impasse anglo-argentino pela disputa das Malvinas, assim como as projeções do impasse chileno-argentino pelo Canal do Beagle. Estas considerações são levadas em conta para desenho da política antártica desses três países. Para uma revisão mais completa das projeções geopolíticas antárticas, consultar o artigo de um dos maiores especialistas nesse tema: CHILD, J. La Antártida y el pensamiento geopolítico sudamericano. In: MONETA, op. cit., p. 185-196.

$43 \mathrm{O}$ assunto da mineração foi considerado tão importante que as reuniões das Partes Consultivas, ao menos temporariamente, passaram a ser anuais. 
VILLA, R. A. D. Atores não-estatais e meio ambiente nas relações internacionais...

decidiram pela moratória de 50 anos, deixando isolada a posição anglo-americana.

O acordo de Protocolo aprovado pelas 26 Partes Consultivas prevê que se algum membro quiser suspender a proibição estipulada tem que convocar uma conferência extraordinária para tratar o assunto. Essa conferência só poderia estipular o fim da proibição com o consentimento absoluto das Partes Consultivas, segundo destaca o artigo 25 do Protocolo. Aliás, ao cabo dos 50 anos do Protocolo, em 2041, a proibição só poderá ser derrogada se fosse aprovada por três quartos do total de Partes Consultivas existentes para esse ano. ${ }^{44}$

O revés anglo-americano não foi encarado com muita satisfação pelas transnacionais americanas do petróleo, pressionando o governo de Bush para que o Protocolo fosse revisto. Essa pressão surtiu efeito: na reunião de junho, quando acreditava-se que a assinatura do Protocolo era só questão de formalidade, o governo americano de Bush surpreendeu o resto das delegações ao anunciar que não assinaria o Protocolo se não fosse revisto o artigo 25. Diante da insistência de lobbies industriais, segundo a imprensa norte-americana, Bush denunciou o artigo 25 do Protocolo, que exige unanimidade para permitir uma eventual prospecção mineral do continente antártico. A atitude de Bush foi criticada pelos demais países, e por organizações ecológicas como o Greenpeace, que haviam lutado para preservar o ecossistema dos interesses econômicos. ${ }^{45}$

A pressão das organizações ecológicas, do Presidente francês Mitterand, do primeiro-ministro australiano Bob Hawke e a imprensa norte-americana, fizeram com que Bush recuasse e assinasse o Protocolo, junto com as outras Partes Consultivas. ${ }^{46}$ É possível que com essa posição contrária, de última hora (que procurava o objetivo declarado de abrir a Antártica à prospecção mineral a qualquer momento), o governo e as mineradoras norte-americanas visassem proteger-se do imponderável de uma conjuntura futura desfavorável em preços altos e estoques baixos de petróleo, situação ante a qual as jazidas alternativas aos centros petrolíferos tradicionais seriam altamente valorizadas.
A assinatura do Protocolo de Madri significou um revés da política exterior americana na região mais austral do mundo. Por outro lado, deve ser interpretada, num caso evidente de jogo soma-zero das relações internacionais, como um claro ganho tanto do bloco das Partes Consultivas comandadas por França e Austrália quanto das ONGs ambientalistas encabeçadas pelo Greenpeace. Se é certo que a França e Austrália não conseguiram a assinatura $a d$ infinitum de uma Convenção de Proteção Ambiental Permanente, também é certo que lograram o objetivo de que, no Protocolo, a Antártica fosse definida como uma "reserva natural, voltada a paz e a ciência". Como declarou o chefe da delegação australiana John McCarthy, "em termos práticos [a proibição de 50 anos] está muito próxima de uma proibição permanente". O mesmo raciocínio pode aplicar-se para as ONGs ambientalistas em relação a sua proposta de um parque mundial para a Antártica, tal como reconhecido por James Jones, do Fundo Mundial pela Natureza: "o que foi acertado na capital espanhola ainda não é um parque mundial mas foi um passo decisivo nessa direção". ${ }^{4}$

O epílogo que se constitui a discussão do Protocolo de Madri não deixa dúvidas sobre a crescente integração de diversos atores políticos internacionais no que diz respeito ao futuro do continente gelado. O que pode acontecer no futuro, ao cabo dos 50 anos do Protocolo, é imprevisível e pode até depender da conjuntura internacional. O importante a destacar, contudo, é que as negociações do regime de minerais e meio ambiente mostraram uma tendência do que no futuro poderá ser uma característica do sistema internacional. A superioridade material, em força e recursos econômicos, nem sempre será o último argumento a dirimir disputas. O sistema internacional tornou-se mais complexo quanto a atores e temas. Surgem, portanto, novos subsídios na política internacional, sendo que os argumentos de atores sem nenhuma ou relativa força material, ao estilo das ONGs ambientalistas, tem a possibilidade de prevalecer em específicos momentos. Não sendo ainda uma realidade é, no mínimo, uma tendência.

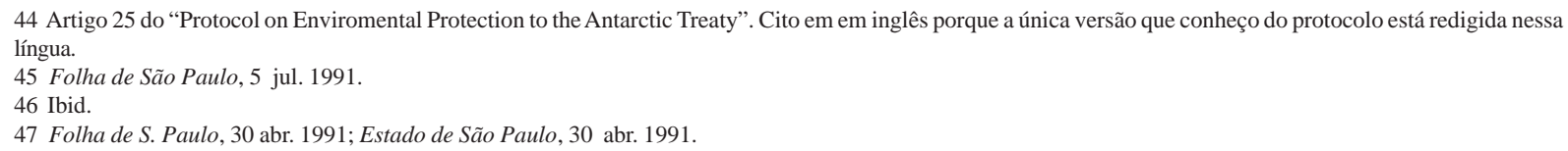


VILLA, R. A. D. Atores não-estatais e meio ambiente nas relações internacionais...

\section{REFER ÊNCIAS}

ARON, R. Os últimos anos do século XX. [S.1.: s.n., 19-].

AUBURN, F. M. Los recursos de los océanos australes y los Estados Unidos. In: MONETA, C. (Ed.). La Antártida en el sistema internacional del futuro. Buenos Aires: Grupo Editor Latinoamericano, 1988.

CHILD, J. La Antártida y el pensamiento geopolítico sudamericano. In: MONETA, C. (Ed.). La Antártida en el sistema internacional del futuro. Buenos Aires: Grupo Editor Latinoamericano, 1988.

DAVIES, B. W. Australia y Antártida: una relación que muda. In: MONETA, C. (Ed.). La Antártida en el sistema internacional del futuro. Buenos Aires: Grupo Editor Latinoamericano, 1988.

DUGGER, J. A. Una mirada hacia las perspectivas del petroleo y el gas en la Antártida. In: MONETA, C. (Ed.). La Antártida en el sistema internacional del futuro. Buenos Aires: Grupo Editor Latinoamericano, 1988.

FOLHA de São Paulo, 30 abr. 1991.

FOLHA de São Paulo, 5 jul. 1991.

GILPIN, R. War and change in world politics. Cambridge: Cambridge University Press, 1989.

GREENPEACE. Antártida en peligro: un problema que concierne al mundo. Buenos Aires: Greenpeace Argentina, [19-].

GREENPEACE. Declaração sobre a Antártida. [S.1.]: Greenpeace, [19-].

GREENPEACE. Informe de la Expedición Antártica de Greenpeace. 1987/1988. Buenos Aires: Greenpeace Argentina, 1988.

GREENPEACE. La opción de protección permanente para la Antártida. Buenos Aires: Greenpeace Argentina, [19-].
HANZAH, B. A. La Antártida y el nuevo regimen internacional. In: MONETA, C. (Ed.). La Antártida en el sistema internacional del futuro. Buenos Aires: Grupo Editor Latinoamericano, 1988.

HEMMING, A. D. Antarctic the earths's fragile alarm bell. Our Planet, v. 2, n. 3, p. 6, 1990.

HOFFMAN, S. International organizations and the International system. International Organization, v. 24, n. 2, 1969.

KAISER, K. Transnational politics: toward a theory of multinational politics. International Organization, v. 25, n. 3, Autumn 1971.

LEIS, H. Ecologia e soberania na Antártica. ENCONTRO DA ASSOCIAÇÃO DE PÓS-GRADUAÇÃO EM CIÊNCIAS SOCIAS, 14., 1990, Caxambu. Anais... Caxambu: [s.n.], 1990.

MENDERSSHUSEN, H. Transnational society vs. state sovereignty. Kiklos, v. 21, n. 2, 1969.

MONETA, C. La Antártida y el Atlántico Sur en el sistema internacional. In: MONETA, C. (Ed.). La Antártida en el sistema internacional del futuro. Buenos Aires: Grupo Editor Latinoamericano, 1988.

O ESTADO do Paraná, 30 abr 1991.

ROSENAU, J. N. Citizens in a changing global order. In: ROSENAU, J. N.; OTTO CZEMPIEL, E. (Eds.). Governance without government: order and change in world politics. Cambridge: Cambridge University Press, 1992.

TOMASSINI, L. El proceso de transnacionalización y las relaciones externas de América Latina. In: TOMASSINI, L. (Comp.). Transnacionalización y desarrollo nacional en América Latina. Buenos Aires: Grupo Editor Latinoamericano, 1984. 